\title{
Color Lookup Table
}

National Cancer Institute

\section{Source}

National Cancer Institute. Color Lookup Table. NCI Thesaurus. Code C94872.

A table used for interpreting pixels (voxels) to find the correspondence between image intensity values and displayed hues for the particular color scale employed. 